\title{
Geometric quality assessment of CBERS-4 MUXCAM image
}

\author{
Avaliação da qualidade geométrica de imagem CBERS-4 MUXCAM
}

\author{
Thiago Statella ${ }^{1}$ \\ ${ }^{1}$ Departamento de Área de Construção Civil, Instituto Federal de Educação, Ciência e Tecnologia de MT - IFMT. Rua \\ Zulmira Canavarros 95. Cep 78032-175. Cuiabá, MT, Brasil. \\ Thiago.statella@cba.ifmt.edu.br
}

Recebido em 05/04/2015 - Aceito em 28/06/2016

Received on 05/04/2015 - Accepted on 28/06/2016

\begin{abstract}
RESUMO - Em dezembro de 2014 Brasil e China lançaram com sucesso o satélite CBERS-4, a quarta geração dos satélites CBERS. No módulo de carga o satélite carrega a MUXCAM, uma câmera multiespectral com 20 m/pixel de resolução espacial. A MUXCAM foi construída sob responsabilidade do Brasil e é uma atualização da câmera CCD de alta resolução dos satélites CBERS-1, 2 e 2B. Neste artigo a qualidade geométrica de uma imagem MUXCAM é analisada. A qualidade geométrica do sensor CCD pode ser medida por meio do cálculo da acurácia posicional e da acurácia interna das imagens adquiridas por ele. A acurácia posicional da MUXCAM resultou em $\sim 404$ m enquanto que a acurácia interna resultou em $\sim 30 \mathrm{~m}$, melhor que dois pixels. Portanto, para aplicações menos rigorosas nas quais uma grande acurácia em coordenadas não seja necessária e em que os erros possam ser negligenciados, as imagens multiespectrais adquiridas pela MUXCAM podem ser usadas sem qualquer correção geométrica.
\end{abstract}

Palavras-chave: Satélite CBERS-4, Acurácia posicional, Acurácia Interna.

ABSTRACT - In December 2014, Brazil and China successfully launched the CBERS-4 satellite, the fourth generation of CBERS satellites. In the payload module, the satellite carries the MUXCAM, a $20 \mathrm{~m} /$ pixel spatial resolution multispectral camera. The MUXCAM was built by Brazil and it is an improvement of the CCD camera on board CBERS-1, 2 and 2B satellites. In this paper the geometric quality of the MUXCAM images is analyzed. One can measure the geometric quality of the CCD sensor by calculating the positioning and the internal accuracy of the images acquired by it. The positional accuracy for the MUXCAM resulted in $\sim 404 \mathrm{~m}$ whereas the internal accuracy resulted in $\sim 30 \mathrm{~m}$, better than 2 pixels. Therefore, in less rigorous applications in which a high accuracy in coordinates is not mandatory, and in which such errors can be neglected, the multispectral images acquired by MUXCAM can be used without a prior geometric correction.

Keywords: CBERS-4 satellite, Positioning accuracy, Internal accuracy.

\section{INTRODUÇÃO}

The China-Brazil Earth Resources Satellite (CBERS) Program is a partnership between Brazil and China in the space technical scientific segment to build and launch Remote Sensing satellites. The first CBERS satellite was launched in 1999 and since then the images generated by the program have been used in important areas, such as deforestation control and environmental monitoring in the Amazon Region, water resources monitoring, urban growth, soil occupation, education and several other applications (LINO et al., 2000; EPIPHANIO, 2013; SILVA et al., 2015).

The fourth CBERS generation (CBERS-4) has been launched in December 2014 from Taiyuan Satellite Launch Center (TSLC) in Shanxi, China. In the payload module CBERS-4 has four cameras: the Panchromatic and Multispectral camera (PANMUX), the Multispectral Camera (MUXCAM), the Infrared Medium Resolution Scanner (IRSCAM) and the Wide Field Imaging Camera
(WIFICAM). The PANMUX and IRSCAM have been built by China whereas the MUXCAM and WIFICAM have been built by Brazil (BOGGIONE et al., 2014).

In this paper the geometric quality of a MUXCAM image has been analyzed. The geometric quality assessment is important to determine and validate the relationship between terrain points and their positions on CBERS-4 images for Remote Sensing applications (D'ALGE et al., 2005). To do so, the positioning accuracy and the internal accuracy of a CBERS-4 MUXCAM image have been analyzed. The positioning accuracy is the average displacement between map projection coordinates that are measured on a system-corrected image and those that are measured on the Earth surface. The internal accuracy is the root mean square error of the remaining residuals after a geometric transformation is applied to tie a system-corrected image to a map projection reference system (D'ALGE et al., 2005). The MUXCAM image has been provided by the Brazilian 
space research national institute (Instituto Nacional de Pesquisas Espaciais - INPE).

\section{MUXCAM IMAGES}

The MUXCAM camera onboard CBERS-4 uses a CCD sensor to acquire $20 \mathrm{~m} /$ pixel spatial resolution images in four spectral bands in a 26 days temporal resolution (EPIPHANIO, 2011; 2013). Table 1 shows some parameters of the MUXCAM.

Table 1- MUXCAM sensor parameters.

\begin{tabular}{ll}
\hline & B1: $0.45-0.52$ \\
Spectral bands $[\mu \mathrm{m}]$ & B2: $0.52-0.59$ \\
& B3: $0.63-0.69$ \\
& B4: $0.77-0.89$ \\
Spatial resolution $[\mathrm{m}]$ & 20 \\
Swath width $[\mathrm{km}]$ & 120 \\
Quantization & 8 bits \\
Revisit [days] & 26 \\
\hline
\end{tabular}

Figure 1 shows the MUXCAM image used to perform the geometric quality assessment of the camera (image credits: DGI-INPE). The scene depicts a number of cities in São Paulo state, among them, part of the São Paulo city (the larger city in the bottom right corner), and has been taken on 01/08/2015. The CBERS-4 systemcorrected image is projected in the Universal Transverse Mercator (UTM) map projection using the WGS84 geodetic reference system Ellipsoid parameters (semimajor axis $a=6378137 \mathrm{~m}$; flattening $f \sim 1 / 298$ ). The scene center coordinates are $23.24041^{\circ} \mathrm{S}$ and $47.04819^{\circ} \mathrm{W}$.

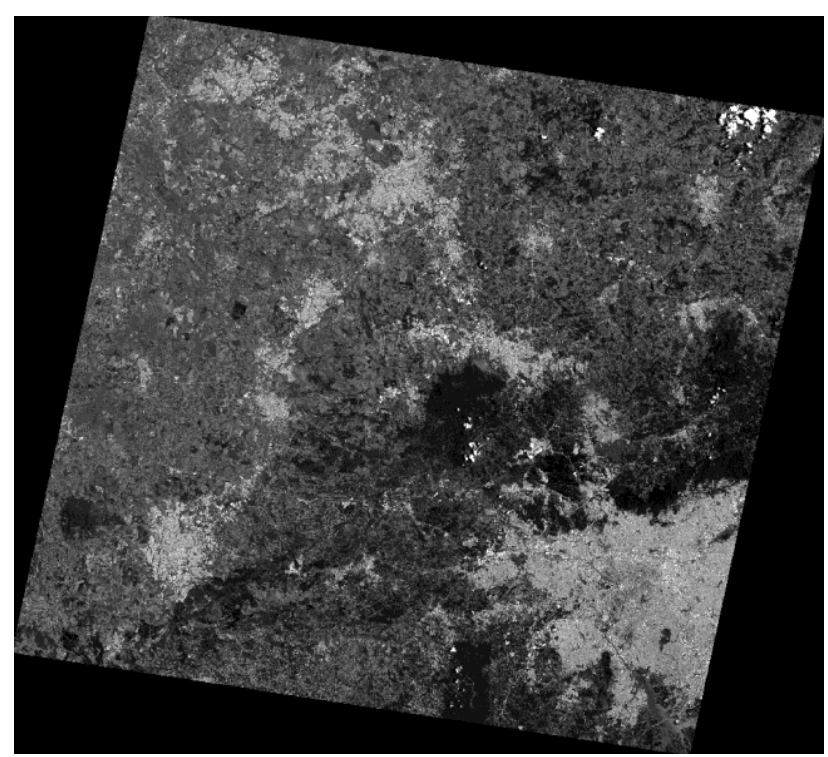

Figure 1 - Multispectral image used to assess the geometric quality of MUXCAM camera onboard CBERS-4 satellite (image credits: DGI-INPE).

\section{METHODOLOGY}

The geometric quality of the CBERS-4 MUXCAM image can be assessed by calculating the positioning accuracy and the internal accuracy of the scenes. In both cases, a set of Ground Control Points (GCPs) is needed. A ground control point is a position easily identified in the MUXCAM image whose corrected map coordinates are accurately known.

\subsection{Positioning accuracy}

The displacement between the system-corrected image coordinates and their map-corrected positions is the positioning accuracy of the image. In the calculations, the system-corrected coordinates of a set of points selected from the MUXCAM image are compared to their mapcorrected coordinates (GCPs coordinates), which can be obtained from GPS measurements, large-scale maps or from ortho-rectified Remote Sensing data. For each point a displacement in $X$ and $Y$ coordinates can be calculated as:

$$
\begin{aligned}
& \Delta X=X_{\text {image }}-X_{G C P} \\
& \Delta Y=Y_{\text {image }}-Y_{G C P} .
\end{aligned}
$$

Where $\left(X_{\text {image }}, Y_{\text {image }}\right)$ are the coordinates from the system-corrected image and $\left(X_{G C P}, Y_{G C P}\right)$ are the GCPs coordinates.

The resulting displacements in $X$ and $Y$ coordinates for a set of $n$ points are given by:

$$
\begin{aligned}
\Delta \bar{X} & =\sqrt{\frac{1}{n} \sum_{i=1}^{n} \Delta X_{i}^{2}} \\
\Delta \bar{Y} & =\sqrt{\frac{1}{n} \sum_{i=1}^{n} \Delta Y_{i}^{2}} .
\end{aligned}
$$

Finally, the total Root Mean Square Error (RMSE) is the positioning accuracy, which is calculated as:

$$
\left(\Delta \bar{X}^{2}+\Delta \bar{Y}^{2}\right)^{1 / 2}
$$

\subsection{Internal accuracy}

After an image has been accurately georeferenced to a map projection system, its internal accuracy can be estimated by measuring the displacement of a set of GCPs coordinates before and after the geometric correction procedure. A geometric transformation is used to relate the system-corrected image coordinates to their georeferenced coordinates. The coordinates of a set of points manually chosen from the georeferenced image is then compared to the map-corrected coordinates of GCPs. Again, GCPs map-corrected coordinates can be obtained from GPS measurements, large-scale maps or from orthorectified Remote Sensing data.

The geometric transformation is usually a polynomial. The choice on the order of the polynomial 
depends on the amount of distortion to be corrected. The higher the order, presumably, the more significant the distortion is. One of the most used transformations for geometric correction of Remote Sensing data is the first order polynomial (or Affine transformation) given in equation 4. It accounts for 6 parameters and therefore requires at least $3 \mathrm{GCPs}$ for them to be solved.

$$
\begin{aligned}
& X_{\text {image }}=a_{1} X_{G C P}+a_{2} Y_{G C P}+a_{3} \\
& Y_{\text {image }}=b_{1} X_{G C P}+b_{2} Y_{G C P}+b_{3} .
\end{aligned}
$$

Where $a_{\mathrm{i}}$ and $b_{\mathrm{i}}, \mathrm{i}=\{1,2,3\}$, are the transformation parameters.

Alternatively, a second order polynomial, such as the one shown in equation 5 , can be applied. That transformation accounts for 12 parameters and therefore requires a minimum of $6 \mathrm{GCPs}$ for them to be solved.

$$
\begin{aligned}
& X_{\text {image }}=a_{1}+a_{2} X_{G C P}+a_{3} \cdot Y_{G C P}+a_{4} X_{G C P} Y_{G C P}+ \\
& a_{5} X_{G C P}^{2} Y_{G C P}+a_{6} X_{G C P} Y_{G C P}^{2} \\
& Y_{\text {image }}=b_{1}+b_{2} X_{G C P}+b_{3} \cdot Y_{G C P}+b_{4} X_{G C P} Y_{G C P}+ \\
& b_{5} X_{G C P}^{2} Y_{G C P}+b_{6} X_{G C P} Y_{G C P}^{2}
\end{aligned}
$$

Where $a_{\mathrm{i}}$ and $b_{\mathrm{i}}, \mathrm{i}=\{1, \ldots, 6\}$, are the transformation parameters.

After applying a first or second order polynomial, the internal accuracy of the image can be assessed by comparing the resulting displacement between the GCPs coordinates and the transformed (georeferenced) image system-corrected coordinates. The procedure for calculating such displacement is the same as for the positioning accuracy, except that in equation 1 the displacements for $X$ and $Y$ are written as $\Delta X=X_{g e o}-X_{G C P}$ and $\Delta Y=Y_{g e o}-Y_{G C P}$, with ( $X_{g e o}, Y_{g e o}$ ) being the transformed coordinates. For the sake of an unbiased analysis, the set of points used for calculating the displacements should be different from the set of points used to estimate the transformation parameters.

\section{RESULTS}

For the positioning and internal accuracy assessment, GCPs have been manually chosen from an ortho-rectified mosaic of RapidEye images. The spatial resolution of the images is $5 \mathrm{~m} /$ pixel and the horizontal accuracy of the GCPs coordinates is $\sim 6 \mathrm{~m}$. The adopted geodetic reference system is the WGS84 and the projection system is the UTM.

\subsection{Assessment of the positioning accuracy}

For the positioning accuracy calculations, a set of 18 GCPs $\left(\mathrm{P}_{\mathrm{i}}, \mathrm{i}=\{1, \ldots, 18\}\right)$ has been selected from the RapidEye mosaic and their coordinates have been compared with the corresponding positions in the MUXCAM image. Figure 2 shows the distribution of the GCPs over the MUXCAM image.

The GCPs must be easily identifiable in both, the MUXCAM image and the reference mosaic. Examples of features that can be used as GCPs are crossing roads, bridges, corners, and any other feature that can be accurately pointed in the scenes. Figure 3 shows examples of manually chosen GCPs. In Figure 3A one can see the ground control point 6 placed over the MUXCAM image. In Figure $3 \mathrm{~B}$ the same control point 6 (in black) and its displacement (in white) in relation to the MUXCAM coordinates are shown over the reference mosaic. Figures $3 \mathrm{C}$ and figure 3D show the same results for the GCP 7 .

Table 2 displays the displacements between MUXCAM point coordinates and the GCPs coordinates measured from the reference mosaic. From Table 2, the resulting displacement in $X$ coordinates is $\Delta \bar{X}=136.59$ $\mathrm{m}$ and for $Y$ coordinates it is $\Delta \bar{Y}=380.07 \mathrm{~m}$. The total RMSE, and therefore the resulting displacement of the MUXCAM image from its expected position, is $\sim 404 \mathrm{~m}$ when considering the whole set of 18 GCPs.

The assessment of the positioning accuracy of the MUXCAM is important because a number of Remote Sensing data users rely on the system-corrected coordinates of the CCD sensor onboard CBERS-4. Thus, they should be aware of the expected error when measuring such coordinates without applying any previous geometric correction to the scenes. The RMSE for CBERS-4 can be considered acceptable if compared, for example, with the CBERS-2 CCD positioning accuracy, which was $\sim 11 \mathrm{~km}$ (D'ALGE et al., 2005; DEVARAJ and SHAH, 2014).

Table 2 - Displacements between coordinates measured in the MUXCAM image and the GCPs coordinates measured in the reference mosaic.

\begin{tabular}{cccc}
\hline Point & $\boldsymbol{\Delta} \boldsymbol{X}[\mathbf{m}]$ & $\boldsymbol{\Delta} \boldsymbol{Y}[\mathbf{m}]$ & RMSE $[\mathbf{m}]$ \\
\hline 1 & -157.354875 & -373.680031 & 405.459396 \\
2 & -159.645159 & -376.336151 & 408.797597 \\
3 & -29.826186 & -364.159737 & 365.379139 \\
4 & -88.737973 & -435.983116 & 444.922134 \\
5 & -143.568341 & -382.614186 & 408.663044 \\
6 & -150.442481 & -346.764871 & 377.993142 \\
7 & -132.170358 & -379.415972 & 401.777903 \\
8 & -120.508222 & -421.154192 & 438.056029 \\
9 & -118.366158 & -417.276847 & 433.740146 \\
10 & -141.036163 & -367.564492 & 393.693859 \\
11 & -140.873023 & -355.237020 & 382.149903 \\
12 & -159.215427 & -392.200328 & 423.285541 \\
13 & -132.991399 & -415.014858 & 435.802758 \\
14 & -152.518604 & -364.638707 & 395.250947 \\
15 & -94.631496 & -313.437827 & 327.411654 \\
16 & -212.769672 & -335.964364 & 397.671959 \\
17 & -93.134184 & -401.376899 & 412.040521 \\
18 & -136.473870 & -376.186707 & 400.176905 \\
\hline
\end{tabular}




\subsection{Assessment of the internal accuracy}

For the internal accuracy assessment, the MUXCAM image has been georeferenced by a geometric transformation used to relate its system-corrected coordinates and the GCPs map-corrected coordinates. Two transformations have been applied, a first and a second order polynomial (according to equations 4 and 5).
In both cases, the same 18 GCPs used to compute the positioning accuracy have been used to estimate the transformation parameters. The RMSE for the first order polynomial after the least square adjustment of the parameters was $39.20 \mathrm{~m}$ whereas the RMSE for the second order polynomial was $34.30 \mathrm{~m}$.

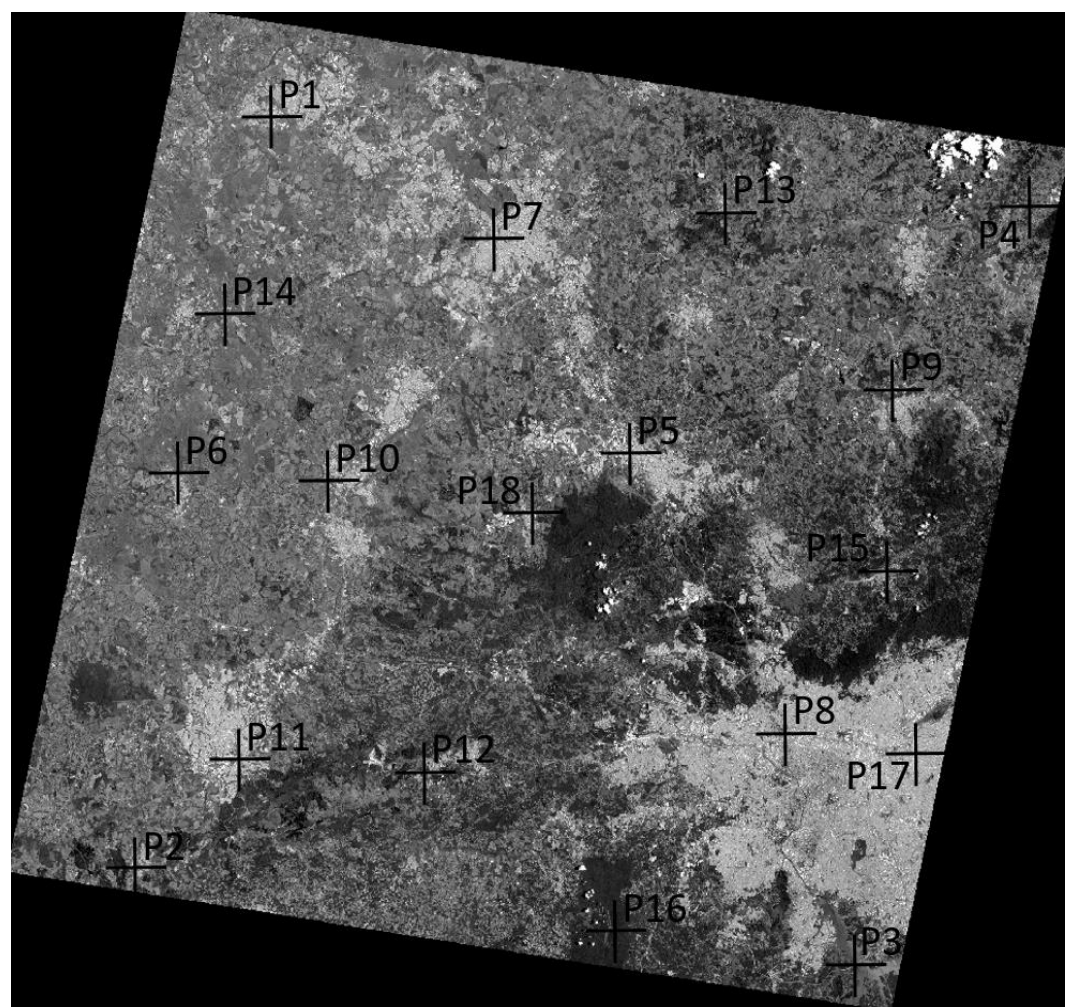

Figure 2 - Distribution of the GCPs over the MUXCAM image. 

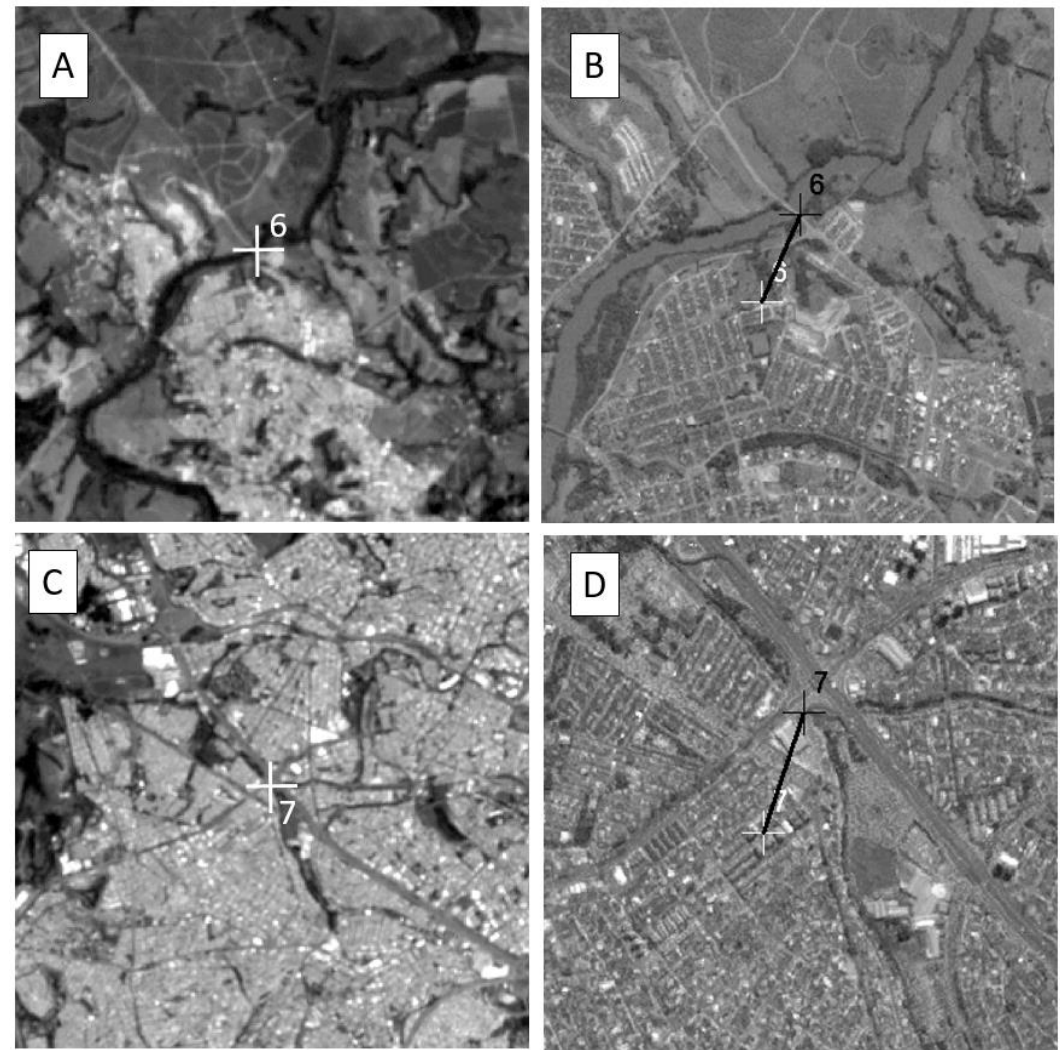

Figure 3 - Manually chosen GCPs: (A) GCP 6 placed over the MUXCAM image. (B) GCP 6 (black) placed over the reference mosaic and its displacement to the MUXCAM coordinates (white). (C) GCP 7 placed over the MUXCAM image. (D) GCP 7 (black) placed over the reference mosaic and its displacement to the MUXCAM coordinates (white).

These results are similar to the ones found by Zanardi et al. (2005) when georeferencing CBERS-1 CCD images.

The displacement measurements were performed over a set of 20 GCPs that had not been used for estimating the geometric transformation parameters. The results are shown in Table 3.

Table 3 - Displacements between coordinates measured in the georeferenced MUXCAM image and the GCPs coordinates measured in the reference mosaic.

\begin{tabular}{cccc}
\hline Transformation & $\Delta \bar{X}[\mathbf{m}]$ & $\Delta \bar{Y}[\mathbf{m}]$ & RMSE $[\mathrm{m}]$ \\
\hline $1^{\text {st }}$ order & 19.80 & 15.47 & 25.12 \\
$2^{\text {nd }}$ order & 20.19 & 22.75 & 30.42 \\
\hline
\end{tabular}

The results were similar for the polynomial transformations considered. The first order RMSE was $25.12 \mathrm{~m}$ whereas the second order RMSE was 30.42 . The MUXCAM CCD camera spatial resolution is $20 \mathrm{~m} / \mathrm{pixel}$, thus the internal accuracy is roughly better than 2 pixels. The higher the internal accuracy, the better the MUXCAM images can be integrated with maps and geospatial data in Geographic Information Systems.

\section{CONCLUSION}

Brazil and China have launched the fourth generation of the CBERS program, the CBERS-4 satellite, in December 2014. Among other scientific instruments, the payload module carries the Multispectral Camera MUXCAM, produced in Brazil. In this paper the geometric quality of an image acquired by the MUXCAM CCD sensor has been assessed by comparing the image coordinates to GCPs coordinates obtained from an orthorectified RapidEye mosaic.

The positioning accuracy for the MUXCAM was $\sim 404 \mathrm{~m}$ with a larger displacement of $\Delta \bar{Y}=380.07 \mathrm{~m}$ found in the NS direction. For coarse applications, the MUXCAM images can be used without any geometric correction but for those applications in which accurate positions are to be measured from the scene a geometric transformation must be applied.

After a geometric transformation has been applied, the coordinates accuracy of the MUXCAM is significantly improved. The internal accuracy has been calculated using a first and a second order polynomial function. The resulting RMSE for the first order polynomial was $25.12 \mathrm{~m}$ and for the second order it was $30.42 \mathrm{~m}$. From the internal accuracy calculations, one can conclude that MUXCAM images can easily be integrated to other maps and spatial data in Geographical Information Systems.

The results obtained for the fourth generation of CCD camera produced in Brazil onboard the CBERS-4 satellite shows a significantly improvement if compared to previous generations, such as CEBERS-2, whose positioning accuracy was $\sim 11 \mathrm{~km}$. 


\section{REFERENCES}

BOGGIONE, G.A., PEREIRA, G., CARDOSO, F.S., FONSECA, L.M.G. Evaluation of simulated images of MUX camera from CBERS-4 satellite for environmental analysis. Boletim de Ciências Geodésicas, vol. 20, p. 590-609, 2014.

D'ALGE, J., CARTAXO, R., ERTHAL, G. Geometric quality assessment of CBERS-2. Proc. XII Simpósio Brasileiro de Sensoriamento Remoto, Goiânia, 16-21 April. 9 p, 2005.

DEVARAJ, C., SHAH, C. Automated geometric correction of multispectral images from $\mathrm{High}$ Resolution CCD camera (HRCC) on-board CBERS-2 and CBERS-2B. ISPRS Journal of Photogrammetry and Remote Sensing, vol. 89, p. 13-24, 2014.

EPIPHANIO, J.C.N. Satélites Brasileiros de Observação da Terra: balanço e perspectivas. Proc. XV Simpósio Brasileiro de Sensoriamento Remoto, Curitiba, 30 April-05 May. 8 p., 2011.

EPIPHANIO, J.C.N. Satélites Brasileiros de Observação da Terra: balanço e perspectivas. Proc. XVI Simpósio Brasileiro de Sensoriamento Remoto, Foz do Iguaçu, 13-18 April. 8 p., 2013.

LINO, C.O., LIMA, M.G.R., HUBSCHER, G.L. CBERSAn international space cooperation program. Acta Astronautica, vol. 47, p. 559-564, 2000.

SILVA, A.G.A., AMARO, V.E., STATTEGGER, K., SCHWARZER, K., VITAL, H., HEISE, B. Spectral calibration of CBERS 2B multispectral satellite images to assess suspended sediment concentration. ISPRS Journal of Photogrammetry and Remote Sensing, vol. 104, p. 53-62, 015.

ZANARDI, R.P., ROLIM, S.B.A., JÚNIOR, C.B., ALMEIDA, C.A.M. Análise de processamento e georreferenciamento em imagens de satélite CBERS1. Proc. XII Simpósio Brasileiro de Sensoriamento Remoto, Goiânia, 16-21 April. 8 p., 2005. 